\title{
A comparison of 2 cesarean section methods, modified Misgav-Ladach and Pfannenstiel-Kerr: A randomized controlled study
}

\author{
Nur Şahin ${ }^{1, A-F}$, Mine Genç ${ }^{1, A, D}$, Gülüzar Arzu Turan ${ }^{1, B, C}$, Esin Kasap ${ }^{2, A-C}$, Serkan Güçlü3,D-F \\ ${ }^{1}$ Department of Obstetrics and Gynecology, Sifa University, Izmir, Turkey \\ ${ }^{2}$ Department of Obstetrics and Gynecology, Karatas Hospital, Izmir, Turkey \\ ${ }^{3}$ Department of Obstetrics and Gynecology, Kent Hospital, Izmir, Turkey \\ A - research concept and design; B - collection and/or assembly of data; C - data analysis and interpretation; \\ $D$ - writing the article; $E$ - critical revision of the article; $F$ - final approval of the article
}

\section{Address for correspondence}

Nur Şahin

E-mail: nurbuldanli@yahoo.com

Funding sources

None declared

Conflict of interest

None declared

Received on June 7, 2016

Reviewed on September 21, 2016

Accepted on October 21, 2016

\begin{abstract}
Background. The modified Misgav-Ladach method (MML) is a minimally invasive cesarean section procedure compared with the classic Pfannenstiel-Kerr (PK) method.

Objectives. The aim of the study was to compare the MML method and the PK method in terms of intraoperative and short-term postoperative outcomes.

Material and methods. This prospective, randomized controlled trial involved 252 pregnant women scheduled for primary emergency or elective cesarean section between 0ctober, 2014 and July, 2015. The primary outcome measures were the duration of surgery, extraction time, Apgar score, blood loss, wound complications, and number of sutures used. Secondary outcome measures were the wound infection, time of bowel restitution, visual analogue scale (VAS) scores at $6 \mathrm{~h}$ and $24 \mathrm{~h}$ after the operation, limitations in movement, and analgesic requirements. At 6 weeks after surgery, the patients were evaluated regarding late complications.

Results. There was a significant reduction in total operating and extraction time in the MML group $(p<0.001)$. Limitations in movement were lower at $24 \mathrm{~h}$ after the MML operation, and less analgesic was required in the MML group. There was no difference between the 2 groups in terms of febrile morbidity or the duration of hospitalization. At 6 weeks after the operation, no complaints and no additional complications from the surgery were noted.
\end{abstract}

Conclusions. The MML method is a minimally invasive cesarean section. In the future, as surgeons' experience increases, MML will likely be chosen more often than the classic PK method.

Key words: cesarean section, postoperative pain, Pfannenstiel incision, modified Misgav-Ladach technique, operating time

DOI

10.17219/acem/66215

Copyright

Copyright by Author(s)

This is an article distributed under the terms of the

Creative Commons Attribution Non-Commercial License

(http://creativecommons.org/licenses/by-nc-nd/4.0/) 


\section{Introduction}

Cesarean sections $(\mathrm{C} / \mathrm{S})$ are among the most common abdominal surgical procedures in women. Approximately $15 \%$ of all deliveries are performed by the abdominal route worldwide. ${ }^{1-3}$ According to the national registry of the Turkish Health Ministry, in 2014 the proportion of abdominal deliveries was $67 \%$ in medical school hospitals, $37 \%$ in public hospitals and $71 \%$ in private hospitals. The percentage at Sifa University Medical School Hospital in 2014 was 65\%.

Cesarean sections are performed in both elective or emergency cases. Fetal distress, a previous C/S history, cephalo-pelvic disproportion, eclampsia, preeclampsia, malpresentation, and placenta previa are the main indications for $C / S$.

Various surgical procedures have been defined for $\mathrm{C} / \mathrm{S}$. In the early $20^{\text {th }}$ century, Pfannenstiel described a transverse incision of the abdomen, which is still the most commonly used method. ${ }^{4}$ In 1926 , Kerr proposed a transverse lower uterine segment incision and double-layer uterine suture with peritoneal closure. ${ }^{5}$ Joel-Cohen described a new transverse incision technique in 1972, and Stark modified it in 1994. ${ }^{6,7}$ This technique is also called the Misgav-Ladach method. In the modified Misgav-Ladach method (MML), skin closure is achieved with continuous subcuticular sutures or clips and mattress stitches, according to the surgeon's preference.

In this prospective study, we sought to compare the MML and Pfannenstiel-Kerr (PK) methods in terms of intraoperative and short-term postoperative outcomes.

\section{Material and methods}

This randomized controlled trial involved 252 pregnant women scheduled for primary emergency or elective C/S. All the procedures were performed at Sifa University
Medical School Hospital between October, 2014 and July, 2015. The approval of the university ethics committee was obtained before beginning the study. Written informed consent was obtained from each patient.

Inclusion criteria were: a gestational age $>36$ weeks, the first $\mathrm{C} / \mathrm{S}$ (the women could have delivered vaginally before) and an obstetric indication for C/S. The same 2 surgeons performed all the $\mathrm{C} / \mathrm{S}$ procedures. Exclusion criteria were: the presence of any additional surgical procedure, such as myomectomy, cystectomy or tubal ligation, placenta previa, placental abruption, preeclampsia, eclampsia, or HELLP syndrome. A flow diagram showing the selection of the study population is presented in Fig. 1. The patients were randomized into 2 groups using a computer-generated random number list: PK $(\mathrm{n}=126)$ and MML $(\mathrm{n}=126)$. The organizer informed the surgeons (SG, NS) of the patient's group assignment immediately before the surgery. The nurses who recorded the VAS scores were blinded to the patient's group. VAS scores were used to assess pain after the operation (on a scale where $0=$ no pain and $10=$ maximum pain). The anesthesiologist decided on the type of anesthesia (general was used in $19 \%$ of the patients, spinal or epidural in $81 \%$ ).

\section{Description of the modified Misgav-Ladach technique}

A Joel-Cohen skin incision was performed with a straight superficial transverse cut in the skin about $3 \mathrm{~cm}$ below the line of the spinae iliacae anteriores superiores, and the subcutaneous tissue was opened upwards in the midline so as to reach the rectus sheath above the insertion of the pyramidalis muscles. ${ }^{7}$ The parietal peritoneum was opened digitally at the upper level of the intermuscular space. The fetus was extracted from a transverse lower uterine segment incision, and the placenta was removed by transabdominal uterine massage combined with light

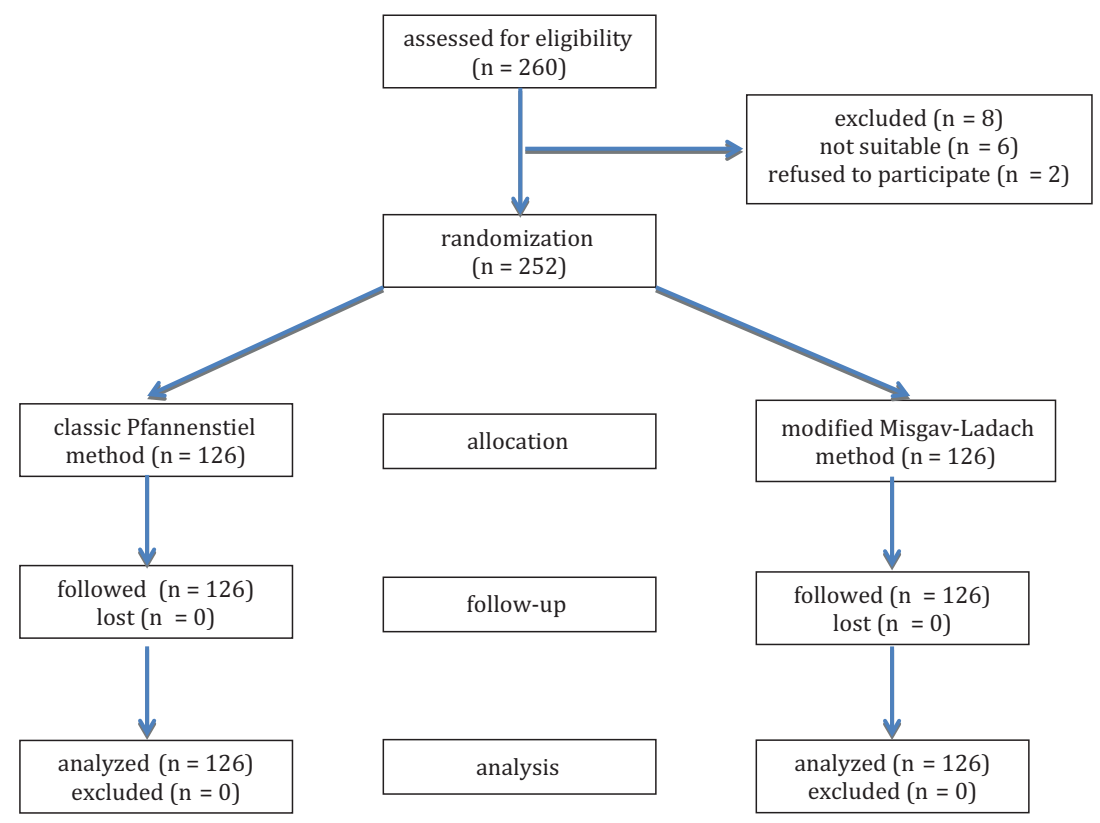

Fig. 1. The selection of the study population 
cord traction. Closure of the uterine incision was accomplished with a 1-layer continuous No. 1 polyglactin 910 suture (Vicryl, Ethicon Inc., Somerville, USA), using additional hemostatic stitches as required. The visceral and parietal peritoneum and the rectus muscles were left unsutured. The rectus sheath was closed using a continuous No. 1 polyglactin 910 suture. The subcutaneous tissue was sutured if its depth exceeded $2 \mathrm{~cm}$. The skin was closed with a continuous subcuticular suture.

\section{Description of the Pfannenstiel-Kerr technique}

The skin was opened with a Pfannenstiel incision, and the incision was extended through the subcutaneous tissue until the rectus sheath was exposed; the latter was then opened in the midline. ${ }^{4}$ Scissors were used to extend the rectus sheath incision laterally, and to separate it from the pyramidalis and rectus muscles. After lateral extension of the uterine incision with uterine scissors, fetal extraction and removal of the placenta using transabdominal uterine massage combined with light cord traction were performed. Closure of the uterine incision was accomplished with a 1-layer continuous No. 1 polyglactin 910 suture. The visceral and parietal peritoneum were closed with a continuous No. 2/0 polyglactin 910 suture. The rectus sheath was closed with a continuous No. 1 polyglactin 910 suture. The subcutaneous tissue was sutured if its depth exceeded $2 \mathrm{~cm}$. The skin was closed with a continuous subcuticular suture.

\section{Primary and secondary measures of postoperative outcomes}

The primary outcome measures were the duration of surgery (between skin incision and skin closure), extraction time (until delivery of the neonate), Apgar score, blood loss, wound complications, and number of sutures used.

Secondary outcome measures were the wound infection, time of bowel restitution, VAS scores from 0 to 10 at $6 \mathrm{~h}$ and $24 \mathrm{~h}$ after the operation, limitations in movement, and analgesic requirements. At 6 weeks after the surgery, patients were evaluated for late complications.

\section{Statistical analysis}

All statistical analyses were performed using RStudio v. 0.98.501 (RStudio Inc., Boston, MA, USA). The MannWhitney U test was used to compare the study groups. Probability values $<0.05$ were considered statistically significant. For each group, a minimum of 126 subjects was required to have $80 \%$ power $(\alpha: 0.05)$ with a $10 \%$ difference in Apgar scores.

\section{Results}

The patient characteristics are shown in Table 1. There was no difference between the groups in terms of mean maternal age, gestational age, BMI, C/S indication, or the type of anesthesia. There was a significant reduction in total operating time in the MML group (16.9 min) compared with the PK group (35.2 min; p < 0.001), and the mean extraction time was significantly shorter in the MML group $(\mathrm{p}<0.001)$. There was no difference in Apgar scores. Primary outcomes are shown in Table 2.

All the patients began a regular diet $6 \mathrm{~h}$ after the surgery and were mobilized at $10 \mathrm{~h}$ after the surgery. The 6-hour post-op VAS score (VAS0) and the 24-hour score (VAS1) were significantly lower in the MML group (MML: 3.54 VAS0, 1.46 VAS1; PK: 6.36 VAS0, 3.64 VAS1; p < 0.001). Limitation in movement, evaluated $24 \mathrm{~h}$ after the operation, was lower in the MML group (Fig. 2), and less analgesic was required in the MML group (1.8 doses; Fig. 3). There were no differences in febrile morbidity or the duration of hospitalization. At 6 weeks after the operation, we received no complaints or reports of additional complications related to the surgery.

Table 1. Patients' demographic data

\begin{tabular}{|l|c|c|c|}
\hline \multicolumn{1}{|c|}{$($ Mean \pm SD) } & $\begin{array}{c}\text { MML } \\
(\mathrm{n}=126)\end{array}$ & $\begin{array}{c}\text { PK } \\
(\mathrm{n}=126)\end{array}$ & p-value \\
\hline Age [years] & $31.4 \pm 4.7$ & $30.2 \pm 5.4$ & 0.080 \\
\hline BMI $\left[\mathrm{kg} / \mathrm{m}^{2}\right]$ & $29.22 \pm 3.97$ & $30.23 \pm 5.09$ & 0.251 \\
\hline Gestational age [weeks] & $38.82 \pm 0.6$ & $38.42 \pm 1.6$ & 0.120 \\
\hline $\begin{array}{l}\text { Type of anesthesia } \mathrm{n}(\%) \\
\text { general } \\
\text { regional }\end{array}$ & $\begin{array}{c}22(17.5) \\
104(82.5)\end{array}$ & $\begin{array}{c}31(23.6) \\
95(76.4)\end{array}$ & 0.155 \\
\hline
\end{tabular}

MML - modified Misgav-Ladach method; PK - Pfannenstiel-Kerr method.

Table 2. Operation details

\begin{tabular}{|l|c|c|c|}
\multicolumn{1}{|c|}{$($ Mean \pm SD) } & $\begin{array}{c}\text { MML } \\
(\mathrm{n}=126)\end{array}$ & $\begin{array}{c}\text { PK } \\
(\mathrm{n}=126)\end{array}$ & p-value \\
\hline Operating time [min] & $16.89 \pm 2.45$ & $35.24 \pm 4.81$ & $<0.001$ \\
\hline Extraction time [s] & $85.2 \pm 40.1$ & $190.3 \pm 78.6$ & $<0.001$ \\
\hline Apgar score (1 min) & $8.8 \pm 2.7$ & $8.3 \pm 2.4$ & 0.121 \\
\hline Blood loss [mL] & $205 \pm 146$ & $370 \pm 251$ & 0.001 \\
\hline Post-op - pre-op [g/dL] & $0.36 \pm 0.95$ & $0.56 \pm 0.83$ & 0.001 \\
\hline Post-op - pre-op [\%] & $0.95 \pm 3.08$ & $1.36 \pm 2.85$ & 0.011 \\
\hline Number of sutures used & $3.2 \pm 1.2$ & $5.3 \pm 2.5$ & 0.001 \\
\hline
\end{tabular}

MML - modified Misgav-Ladach method; PK - Pfannenstiel-Kerr method.

\section{Discussion}

The present study compared the PK and MML methods. In recent studies, shorter operating times have been reported with MML. ${ }^{8-12}$ Franchi et al. reported similar operating times with both methods, but a shorter extraction 


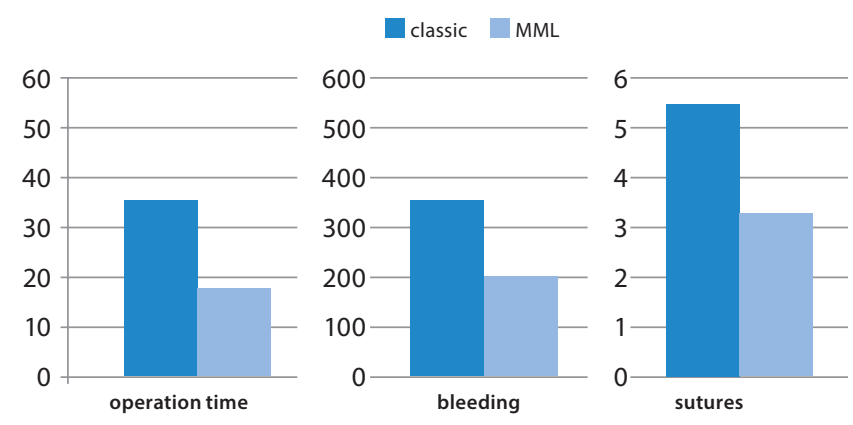

Fig. 2. Comparison of primary outcomes

(operating time in min; bleeding in $\mathrm{mL}$; sutures by number)

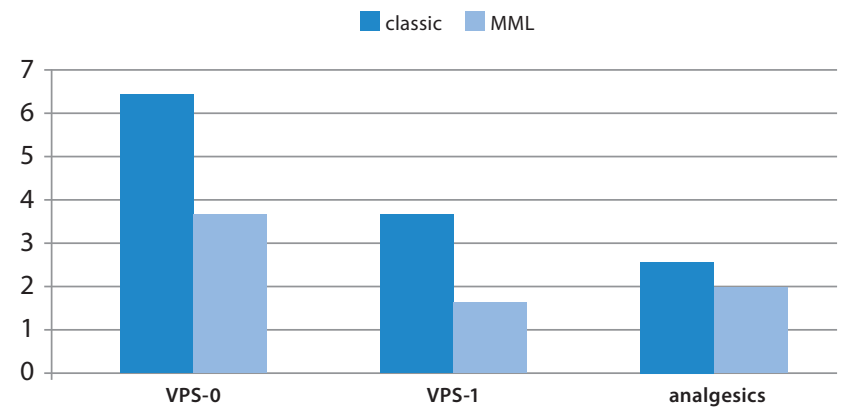

Fig. 3. Comparison of secondary outcomes

(VAS scores and analgesics by number)

time with MML. ${ }^{13}$ We also found a shorter operating time with MML than with the PK method. A shorter operating time may be particularly important in emergencies as opposed to elective cases. It is of primary importance that the duration between incision and entrance to the abdomen was shorter, which provides a shorter time for delivering the baby. Although better results for neonatal outcomes would be expected under this condition, in most studies addressing this issue, no difference has been reported for neonatal outcomes between the 2 methods. ${ }^{9,10,13,14}$ We also found no difference in Apgar scores between the groups.

Another reason for the shorter operating time with MML is that the visceral and parietal peritoneal layers were left unsutured after the closure of the uterus. Suturing the peritoneal layers is an unnecessary step, because the peritoneum does not heal by the approximation of the wound edges; a new peritoneal layer is formed within $24-48 \mathrm{~h}$. Adhesions are formed as vascular bridges to supply oxygen to ischemic areas of tissue, and necrosis often occurs around peritoneal sutures, providing focal points for adhesions. ${ }^{15-17}$ Moreover, leaving the subcutaneous tissue unsutured does not increase the incidence of wound complications. ${ }^{18,19}$ In the present study, we found that significantly fewer sutures were used in the MML group. The reduction in cost achieved in the MML method by using fewer sutures and less anesthesia is particularly important for developing countries.

Stark and Finkel demonstrated reduced use of antibiotics and less postoperative febrile morbidity with MML. ${ }^{7}$ However, other studies have found similar results for wound infection in the 2 methods. ${ }^{9,20}$ A prophylactic antibiotic was given to all the patients in the present study, and we did not note any infection in either group. As in other recent studies, we found significantly less blood loss in the MML group. ${ }^{21}$ This was associated with several procedural differences: the subcutaneous tissue was not cut, the rectus muscles were stretched instead of being cut and the fascia layer was not opened upwards from the midline.

All the procedures were performed by the same 2 experienced surgeons to avoid variation. A nurse blinded to the patient group recorded the postoperative data (VAS scores, the need for analgesics, scores for movement limitation) to prevent bias during the study. Early mobilization is known to reduce the risk of thrombosis, ileus and infections. Early restitution of oral intake facilitates physical recovery through rapid replacement of protein loss. The lower analgesic requirements during the early postoperative period in the MML group are associated with lower tissue trauma due to blunt access to the abdominal cavity, without the blood vessels and nerves of the subcutaneous tissue being incised. ${ }^{19}$

Higher scores were recorded for VAS0 and VAS1 in the PK group than the MML group in our study. The patients in the MML group reported less postoperative discomfort, indicating that MML is a less traumatic $\mathrm{C} / \mathrm{S}$ approach. In another study, it was demonstrated that the MML method resulted in better short-term quality of life scores, especially in terms of reduced bodily pain and postoperative complications compared with the PK method. ${ }^{17}$

\section{Conclusions}

We suggest that in the future, with increased experience on the part of surgeons, the minimally invasive MML cesarean section method will be chosen more often than the classic PK method.

\section{References}

1. Menacker F, Curtin SC. Trends in cesarean birth and vaginal birth after previous cesarean, 1991-1999. Natl Vital Stat Rep. 2001;49(13):1-16.

2. Thomas J, Paranjothy S; Royal College of Obstetricians and Gynaecologists Clinical Effectiveness Support Unit. The National Sentinel Caesarean Section Audit Report. London: RCOG Press; 2001.

3. Cai WW, Marks JS, Chen CH, Zhuang YX, Morris L, Harris JR. Increased caesarean section rates and emerging patterns of health insurance in Shanghai, China. Am J Public Health. 1998;88:777-780.

4. Pfannenstiel J. On the advantages of a transverse cut of the fascia above the symphysis for gynecological laparotomies, and advice on surgical methods and indications. SammI Klin Vortr Gynakol. 1987; 68:1-22.

5. Kerr JMM. The technic of cesarean section with special reference to the lower uterine segment incision. Am J Obstet Gynecol. 1926;12: 729-734.

6. Joel-Cohen S. Abdominal and Vaginal Hysterectomy: New Techniques Based on Times and Motion Studies. London: Heinemann; 1972.

7. Stark M, Finkel AR. Comparison between the Joel-Cohen and Pfannenstiel incisions in cesarean section. Eur J Obstet Gynecol Reprod Biol. 1994;53:121-122.

8. Song SH, Oh MJ, Kim T, Hur JY, Saw HS, Park YK. Finger-assisted stretching technique for cesarean section. Int J Gynaecol Obstet. 2006;92(3):212-216. 
9. Bjorklund K, Kimaro M, Urassa E, Lindmark G. Introduction of the Misgav Ladach caesarean section at an African tertiary centre: A randomised control trial. BJOG. 2000;107(2):209-216.

10. Darj E, Nordstrom ML. The Misgav Ladach method for cesarean section compared to the Pfannenstiel method. Acta Obstet Gynecol Scand. 1999;78(1):37-41.

11. Wallin G, Fall O. Modified Joel-Cohen technique for caesarean delivery. BJOG. 1999;106(3): 221-226.

12. Xavier P, Ayres-De-Campos D, Reynolds A, Guimaraes M, Costa-Santos C, Patricio B. The modified Misgav-Ladach versus the Pfannenstiel-Kerr technique for cesarean section: A randomized trial. Acta Obstet Gynecol Scand. 2005;84(9):878-882.

13. Franchi M, Ghezzi F, Raio L, et al. 2002. Joel-Cohen or Pfannenstiel incision at cesarean delivery: Does it make a difference? Acta Obstet Gynecol Scand. 2002;81:1040-1046.

14. Naki MM, Api O, CelikH, Kars B, Yasar E, Unal O. Comparative study of Misgav-Ladach and Pfannenstiel-Kerr cesarean techniques: A randomized controlled study. JMatern Fetal Neonatal Med. 2011;24 (2): 239-244.

15. Malvasi A, Tinelli A, Farine D, et al. Effects of visceral peritoneal closure on scar formation at cesarean delivery. Int J Gynaecol Obstet. 2009;105:131-135.
16. Malvasi A, Tinelli A, Guido M, Zizza A, Farine D, Stark M. Should the visceral peritoneum at the bladder flap closed at cesarean sections? A post-partum sonographic and clinical assessment. J Matern Fetal Neonatal Med. 2010;23: 662-669.

17. Fatusic Z, Hudic I, Sinanovic O, Kapıdzıc M, Hotic N, Music A. Short-term postnatal quality of life in women with previous Misgav Ladach caesarean section compared to PhannenstielDorffler caesarean section method. J Matern Fetal Neonatal Med. 2011;24(9):1138-1142.

18. Federici D, Lacelli B, Muggiasca L, Agarossi A, Cippolla L, Conti M. Cesarean section using the Misgav Ladach method. Int J Gynaecol Obstet. 1997;57(3):273-279.

19. Kulas T, Habek D, Karsa M, Vukovic M. Modified Misgav Ladach method for cesarean section: Clinical experience. Gynecol Obstet Invest. 2008;65:222-226.

20. Franchi $M$, Ghezzi $F$, Balestreri $D$, et al. A randomized clinical trial of two surgical techniques for cesarean section. Am J Perinatol. 1998; 15:589-594.

21. Li M, Zou L, Zhu J. Study on modification of the Misgav Ladach method for cesarean section. J Tongji Med Univ. 2001;21(1):75-77. 